\title{
Post-etching cleaning influences the resin shear bond strength to CAD/CAM lithium-disilicate ceramics
}

\author{
Greciana Bruzi ${ }^{1,6^{*}}$, Adriana Oliveira Carvalho², Marcelo Giannini ${ }^{3}$, Hamilton Pires Maia ${ }^{4}$ and Pascal Magne ${ }^{5}$
}

\author{
*Correspondence: \\ greciana.brasil@unifal-mg. \\ edu.br; kikaodonto@yahoo. \\ com.br \\ ${ }^{6}$ St. Figueira da foz 44. \\ Aldeia de Sagres, Lavras, MG \\ 37200-000, Brazil \\ Full list of author information \\ is available at the end of the \\ article
}

\begin{abstract}
Statement of problem: The hydrofluoric acid (HF) is able to promote selective dissolution of the glassy phase in silica-based ceramic. However, the etching leaves insoluble silica-fluoride salts in the surface that affects negatively the bond, affirming the need of a post-etching cleaning.

Purpose: Evaluate the shear bond strength (SBS) of composite resin to CAD/CAM lithium-disilicate ceramics after different post-etching cleaning and silane treatments.

Methods: Twenty-four 2 mm-thick slices of IPS e.max CAD (Ivoclar Vivadent, AG, Schann, Liechtenstein) were crystallized, embedded in acrylic resin, polished and cleaned in an ultrasonic bath. Each specimen was etched with 5\% HF for 20 s, rinsed for $60 \mathrm{~s}$, and treatment was completed using surface cleaning and silanization. The cleaning methods were: AW—air/water spray; UB — ultrasonic bath; PA— $37 \%$ phosphoric acid; and ST_-steam cleaning. The cleaned surface received: $\mathrm{E}$ - no silane treatment; E/S - silane application for $20 \mathrm{~s}$, air drying for $20 \mathrm{~s}$ and hot drying $\left(60^{\circ} \mathrm{C}\right)$ for $20 \mathrm{~s}$; E/S+一silane application for $60 \mathrm{~s}$, air drying for $20 \mathrm{~s}$, hot air drying $\left(60^{\circ} \mathrm{C}\right)$ for $20 \mathrm{~s}$, rinsing with boiling water for $15 \mathrm{~s}$ and hot air drying for $20 \mathrm{~s}$. Cylinders of composite resin $(n=12)(Z 100,3 M-E S P E$, Saint Paul, MN, USA) were bonded using an adhesive resin (Optibond FL adhesive, Kerr Corp, Orange, CA, USA). SBS testing was carried out after $24 \mathrm{~h}$ of storage in water. Samples for each post-etching cleaning regimen were analyzed by SEM.
\end{abstract}

Results: According to two-way ANOVA (Bonferroni-corrected post hoc tests, $\mathrm{p}<0.05$ ), the SBS was significantly influenced by the post-etching cleaning, with UB yielding the highest SBS (21 MPa for E/S); other post-etching cleaning regimens showed lower SBS values (12-17 MPa). The type of silane application was not significantly different. The SEM analysis showed a cleaner ceramic surface for UB when compared to the other groups.

Conclusions: Etching lithium disilicate ceramics following by ultrasonic bath cleaning and regular application of a silane is recommended.

Keywords: Adhesion, Ceramic, Silane, Neutralization

\section{Background}

Bonding to silica-based ceramics requires micro mechanical (hydrofluoric-acid, HFetching) and chemical (silane) coupling [1-5]. The HF-etching provides dissolution of

(c) The Author(s) 2017. This article is distributed under the terms of the Creative Commons Attribution 4.0 International License (http://creativecommons.org/licenses/by/4.0/), which permits unrestricted use, distribution, and reproduction in any medium, provided you give appropriate credit to the original author(s) and the source, provide a link to the Creative Commons license, and indicate if changes were made. 
the glassy and/or crystalline phase [6], forming tetrafluorosilane, which further reacts with HF to form a soluble hydrofluorosilicic acid that dissolves the glassy matrix. As a consequence, a micro-retentive and high energy surface is obtained [7-9]. On the other hand, the coupling molecule, $\gamma$-methacryloxypropyl trimethoxysilane, an organofunctional silane, works like a bridge with two different reactive functional groups. The silane molecule can chemically bond to the hydrolyzed silicon dioxide at the ceramic surface ($\mathrm{Si}-\mathrm{O}-\mathrm{Si}-$ siloxane bond) and the methacrylate group can copolymerize with the adhesive resin $[5,10]$. Silane coupling agents allow improved resin wettability of the etched ceramic surface and provide a covalent bond with the methacrylate groups in the resin and the ceramic surface $[4,5]$. The stability and effectiveness of this adhesion can be enhanced by heat treatment $[4,11-14]$ or optimized silane application $[15,16]$. Optimal silane application implies the elimination of water, alcohol and other solvents, allowing for the complete condensation reaction to form the siloxane bond (heat treatment) and eliminate excess silane oligomers to obtain a monolayer of silane (hot water rinsing) $[4$, 15-17].

HF-etching is known to leave residual salts of silica fluoride that precipitate [1820] and can be identified as a white deposit on the etched ceramic surface. Leaving this debris could negatively influence the resin bond strength [21, 22]. Several cleaning methods have been suggested to remove those debris, including ultrasonic cleaning in distilled water, 95\% alcohol or acetone [19, 21, 22]. Some authors have described the association between brushing the surface with phosphoric acid and immersion in an ultrasonic bath to remove the crystalline debris from the etched surface [21]. It is agreed that the resistance of the resin-ceramic adhesion zone is controlled primarily by the microstructure and surface treatment of the ceramic $[6,22,23]$. Each new material or product must therefore be studied individually to define the optimal bonding protocol. Lithium-disilicate ceramics are among those new materials that have been marketed with great success and deserve special attention for increasing the limited knowledge database regarding optimal resin bonding techniques.

The purpose of this study was to evaluate the influence of different post-etching cleaning and silane application techniques on the resin shear bond strength (SBS) to CAD/ CAM ceramics (IPS e.max CAD). The first null-hypothesis tested was that there would be no difference between the post-etching cleaning techniques investigated. The second null-hypothesis was that the silane treatment would have no significant influence on the bond strength of composite resin to lithium disilicate CAD/CAM ceramics.

\section{Methods}

Twenty-four slices $(14 \times 16 \times 2 \mathrm{~mm})$ of IPS e.max CAD LT A2/C14 (EMAX; Ivoclar Vivadent, AG, Batch R28294) were obtained by sectioning CAD/CAM blocks using a slow-speed diamond water-cooled saw (Isomet, Buehler). The slices were crystallized in a ceramic furnace (Austromat 624; DEKEMA Dental-Keramiköfen $\mathrm{GmbH}$ ) following the manufacturer's instructions. The slices were embedded in an acrylic resin positioning base (Palapress; Heraeus Kulzer, $\mathrm{GmbH}$ ) and polished manually with 400- and 600-grit silicon carbide paper under water cooling. The surface of all specimens was then cleaned in an ultrasonic bath with distilled water for $5 \mathrm{~min}$. All specimens were HF-etched (IPS Ceramic Etching Gel, Ivoclar Vivadent $-<5 \%$ ) for $20 \mathrm{~s}$, rinsed for $60 \mathrm{~s}$ with air/water 
spray (40 psi/2,76BAR) followed by post-etching cleaning and silanization. Four different post-etching cleaning methods were compared: AW-air/water spray, no post-etching cleaning; UB-immersion in ultrasonic bath with distilled water for $2 \mathrm{~min}$; PA-application of phosphoric acid (37\%) for $30 \mathrm{~s}$, followed by rinsing with water; or ST-steam cleaning (AX-SCA dental steam cleaner) for $10 \mathrm{~s}$ at $4-5$ bars and a $10 \mathrm{~cm}$ distance. For each post-etching cleaning method, two silane application methods were used: E-no silane treatment; E/S-silane (Silane, Ultradent) applied for $20 \mathrm{~s}$ and air dried for $20 \mathrm{~s}$, hot dried at $60^{\circ} \mathrm{C}$ for $20 \mathrm{~s}$; or E/S+-silane applied for $60 \mathrm{~s}$, air dried for $20 \mathrm{~s}$ and hot air dried $60{ }^{\circ} \mathrm{C}$ for another $20 \mathrm{~s}$ (with hair dryer at $10 \mathrm{~cm}$-distance), rinsed with boiling water for $15 \mathrm{~s}$ and hot air dried for $20 \mathrm{~s}$.

The conditioned ceramic slices were placed in a positioning device and a Teflon mold (Ultradent Jig) containing a $0.04448 \mathrm{~cm}^{2}$ bonding area was used to build composite resin cylinders. First, an adhesive resin (Optibond FL Adhesive, Kerr Corp.) was applied to the ceramic, then the restorative composite resin, Z100 (3M ESPE), was inserted into the mold in two increments of approximately $1.8 \mathrm{~mm}$ each using a small condensing spatula. Each increment was light polymerized for $20 \mathrm{~s}$ (Valo, Ultradent) at $1000 \mathrm{~mW} / \mathrm{cm}^{2}$. Six resin cylinders (diameter: $2.4 \mathrm{~mm}$ ) were built onto each ceramic slice (length: $15 \mathrm{~mm}$, width: $4 \mathrm{~mm}$, thickness: $2 \mathrm{~mm}$ ), $3.5 \mathrm{~mm}$ apart, resulting in 12 specimens per group. After $24 \mathrm{~h}$ storage in distilled water, the samples were submitted to SBS testing (Shear Bond Tester; Bisco Inc.) using a ramp load of 43.8-kg-force per minute. The failure mode was assessed by macrophotography (Nikon D60 and Sigma Lens $105 \mathrm{~mm}$ ).

An additional etched ceramic slice was produced for each post-etching cleaning regimen and analyzed by SEM.

\section{Statistical analysis}

The Shapiro-Wilk test was applied to each group (post-etching cleaning and silane) and between the experimental groups to verify the normality $(p=0.200)$. Homogeneity of the variance of Levene $(\alpha=0.05)$ was achieved $(p=0.387)$. The mean bond strength and standard deviation were calculated for all groups. Statistical analysis was performed using a two-way analysis of variance (ANOVA), in which post-etching cleaning and silane application methods served as independent factors. The Bonferroni post hoc test was used for equal variances to test the average values of all groups. The significance level adopted in all analyses was $\leq 0.05(\mathrm{p}<0.05)$ (MedCalc Software for Windows version 12.3.0).

\section{Results}

According to two-way ANOVA and Bonferroni post hoc $(\mathrm{p}<0.05)$ (Table 1), the SBS was influenced significantly by the type of post-etching cleaning, with UB yielding the highest SBS (E/S $=21 \mathrm{MPa}$ when combined with silane) $(\mathrm{p}<0.001)$. Other post-etching cleaning methods (AW, PA, and ST) showed lower SBS values (12-17 MPa, independent of the silane technique) $(\mathrm{p}<0.001)$. The type of silane application was not significantly different. The factorial interaction was significant, showing that the effectiveness of the cleaning method was influenced by the silane application technique (Table 2). The failure mode was always adhesive, leaving a clean ceramic surface (Fig. 1). 
Table 1 Two-way ANOVA for experimental groups

\begin{tabular}{llccrr}
\hline Source & DF & Sum of square & Mean square & F & \multicolumn{1}{c}{$\mathbf{p}^{*}$} \\
\hline Groups & 2 & 318.5 & 4.18 & 0.37 & 0.689 \\
Post-etching cleaning & 3 & 8.3 & 106.19 & 9.46 & $<0.001$ \\
Group x Post-etching cleaning & 6 & 83.58 & 11.21 & 7.45 & $<0.001$ \\
\hline
\end{tabular}

${ }^{*} \mathrm{p}<0.05$ indicates statistically significant differences

Table 2 Mean SBS value in MPa (SD)

\begin{tabular}{lllll}
\hline & Water spray & Ultrason bath & Phosphoric acid & Steam \\
\hline Group E & $16.92(3.55) \mathrm{b}$ & $15.15(3.82) \mathrm{cb}$ & $14.00(2.49) \mathrm{cb}$ & $14.70(3.01) \mathrm{cb}$ \\
Group E/S & $14.22(3.21) \mathrm{cb}$ & $21.06(4.06) \mathrm{a}$ & $11.90(2.49) \mathrm{c}$ & $12.49(3.63) \mathrm{cb}$ \\
Group E/S+ & $12.05(2.37) \mathrm{c}$ & $15.93(2.53) \mathrm{cb}$ & $14.18(3.44) \mathrm{cb}$ & $16.25(4.42) \mathrm{cb}$ \\
\hline
\end{tabular}

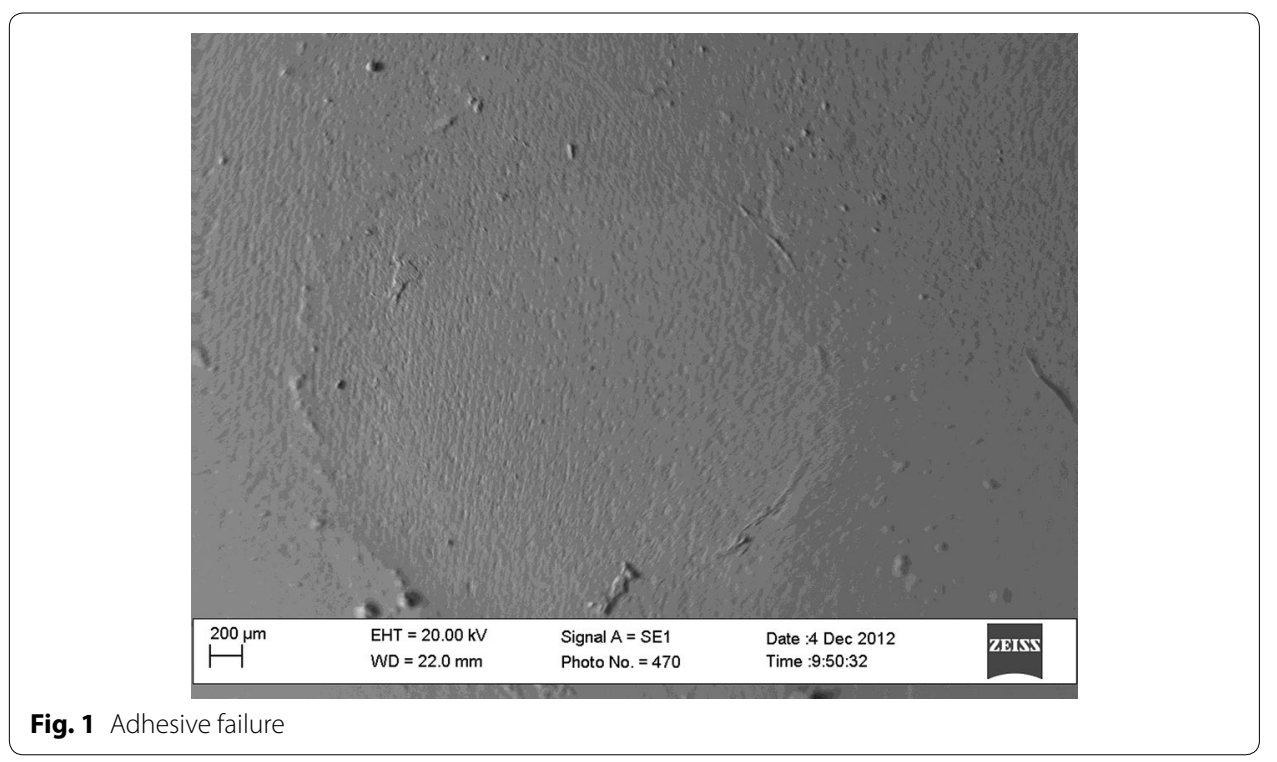

The SEM analysis of etched ceramic slices showed a cleaner surface when UB was used as a post-etching cleaning. The other groups, AW, PA and ST, showed residues deposited on the ceramic surface (Figs. 2, 3, 4 and 5).

\section{Discussion}

The results of this study lead to the rejection of the first null-hypothesis, since post-etching cleaning methods had an influence on the SBS of lithium disilicate ceramics. The second null hypothesis was accepted, as the SBS values were not influenced by the various silane application techniques.

The bonding strength between the resin luting agents and the ceramic can be measured in vitro using several methods (shear, micro-shear, tensile and microtensile). The principle of those tests is to apply a load that creates stress at the adhesive interface until failure is observed. However, none of these tests are accepted as a universal method and 

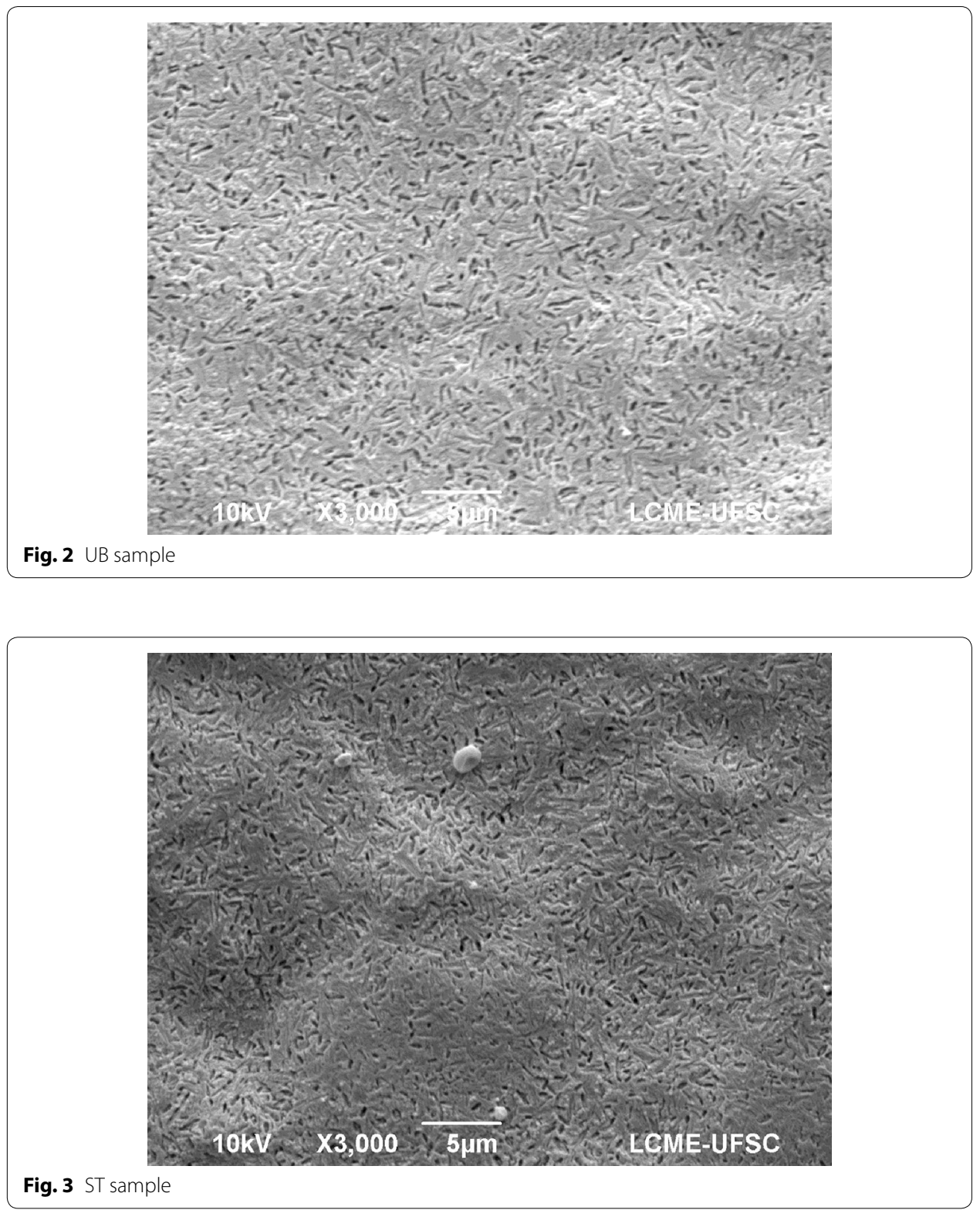

each of them have their own advantages and limitations. In this regard, the microtensile bond strength (MTBS) test is usually preferred because it generates uniform stress distribution across the adhesive interface [24], limiting the possibility of cohesive failure of the substrate [25]. Despite those advantages, MTBS is a technique-sensitive method, it can present a high frequency of premature failures [26], it can be affected by cutting speed [27], shape of the sample [28] and the brittleness of the substrate [27, 28]. On the other hand, the SBS test is considered the most common and practical bond test, as it avoids the steps of specimen sectioning and trimming, which can introduce early micro-cracking of brittle substrates [27-29]. As a result, some authors have concluded that a shear approach was more appropriate when compared to a microtensile approach [30, 31]. In this present study, the SBS testing method was selected since the substrate was strong enough to prevent cohesive failures. Strengthened ceramic substrates, such 


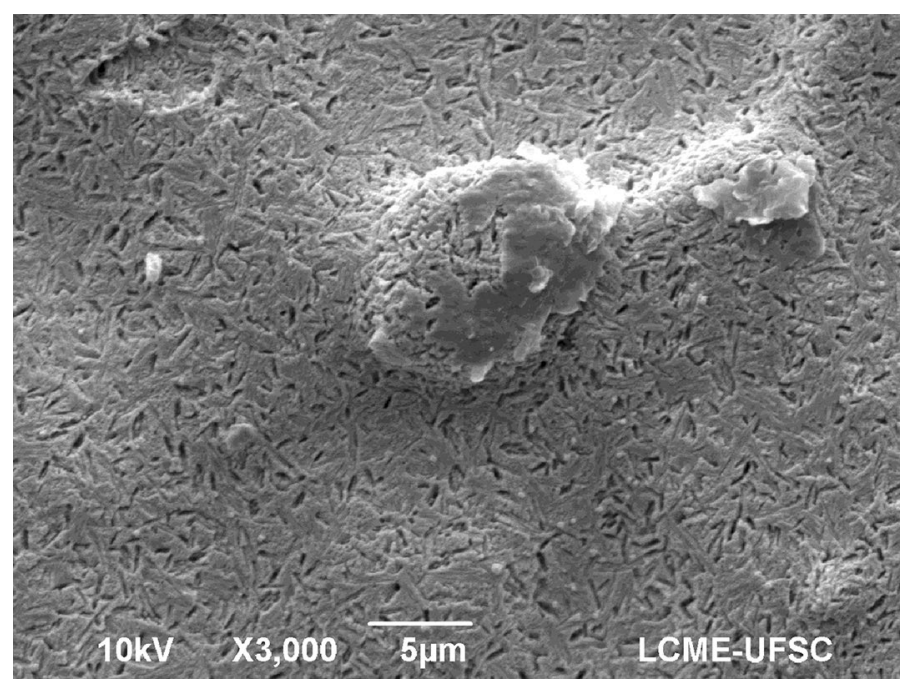

Fig. 4 AW sample

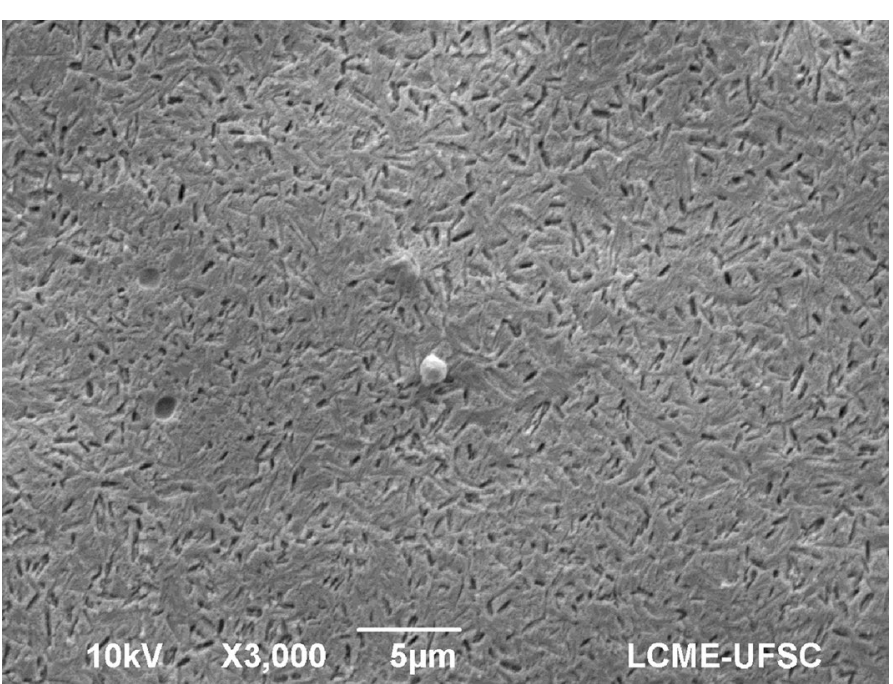

Fig. 5 PA sample

as zirconia and lithium-disilicate, can be deemed appropriate for testing resin bond strength using SBS tests.

It is accepted that conditioning of lithium disilicate by HF-etching requires a shorter etching time and HF concentration ( $20 \mathrm{~s}, 5 \% \mathrm{HF}$ ) possibly because of the reduced crystal size; the less glass in the ceramic to be removed and also since excessive etching might cause a weakening of the ceramic substrate [23]. Dissolution of the vitreous phase creates 5-20 $\mu$ m-deep micro-retentions [22, 24, 32, 33] that can be resin-infiltrated [22]. Micromechanical retention generated by HF-etching seems to be the main mechanism for bonding to lithium disilicate ceramics [4]. Additional use of silane did not seem to bring any benefit, unless ultrasonic post-etching cleaning was used. Maybe the usage of the silane didn't show statistical difference due to the presence of insoluble salts in 
the surface. Insoluble salts may interfere in the interaction between the silane and the silica, leading to lower bond strength values, not because the silane does not need to be used. So it will require an adequate cleaning of the surface before the use of the silane. The side effect of HF-etching is the formation of insoluble residual salts that precipitate and obliterate microretentions [18-20,22], which may significantly influence the bond strength values [18, 22], confirming the need for post-etching cleaning [21, 22]. Most authors support the post-etching protocol used in this current study (ultrasonic distilled water bath for $2 \mathrm{~min}$ ) to provide effective residue elimination [19, 21, 34]. One study failed to demonstrate the effectiveness of post-etching ultrasonic cleaning [35], although this can be explained by the fact that specimens were placed in the ultrasonic bath for $20 \mathrm{~min}$, which may have caused weakening or disaggregation of the etched porcelain. In another study, post-etch cleaning led to a 100\% increase in MTBS (24 MPa without cleaning vs. $50 \mathrm{MPa}$ with cleaning). In the present study, the maximum gain from postetching cleaning was only $30 \%$ (from $14 \mathrm{MPa}$ up to $21 \mathrm{MPa}$ ). This could be explained by the small amount of residue observed on the etched surface of lithium disilicate ceramics [22], possibly due to the reduced vitreous content $[6,36]$ and the reduced time for etching. The other post-etching cleaning techniques used in this present study (air/water spray, phosphoric acid or steam) performed similarly and did not improve or reduce bond strength, which is in agreement with Swift, Walls and McCabe [37].

The use of a silane coupling agent induces encapsulation of the etched protruding crystals [24] and allows for continuity between the organic and inorganic phases [5, 10]. According to Hooshmand et al. [15]. and Queiroz et al. [16], application of a silane induces the formation of a complex interphase with several distinctive layers. The layer closest to the substrate is a monolayer of coupling silane, the only layer necessary for optimal bonding. It is usually covered by two consecutive layers of oligomers, a first layer which can be hydrolyzed only by hot water and a second layer of loosely bound oligomers that can be removed by water at room temperature. Those two outer layers appear to weaken the interphase because of their sensitivity to hydrothermal attacks. The monolayer appears to be chemically reacted (siloxan covalent bond) and can resist hydrothermal attacks. Heat-drying the silane appears to consolidate the three regions by facilitating and stabilizing the siloxane bond. Combining heat drying and hot water rinsing has been advocated by Hooshmand [38] and presented as the optimal silane application technique. The present study did not confirm those results because the optimal silane application was used $(\mathrm{E} / \mathrm{S}+)$ and did not yield improved bond strength. One possible explanation is the fact that the silane was applied for only $20 \mathrm{~s}$ in group $\mathrm{E} / \mathrm{S}$ (as compared to $60 \mathrm{~s}$ in other studies), which may have been too short for the development of the weak outer oligomer layers. The systematic use of heat drying may also have resulted in the consolidation of the silane layers, which could have masked the effect of hot water rinsing.

Even though there seemed to be have been a synergetic effect of post-etching cleaning and the simplified silane application (E/S group), further studies should determine the optimal silane application time that would provide a sufficient number of molecules to saturate the surface of the ceramic (allowing all exposed silica from the substrate to form a siloxane bond) while simultaneously preventing the formation of excess loosely bound silane layers. The application time varies excessively in the informations of most popular products: $5 \mathrm{~s}$ for Ceramic Primer (3M), $30 \mathrm{~s}$ for Bis-silane (BISCO), and $60 \mathrm{~s}$ 
for Monobond S (Ivoclar-Vivadent) and Silane (Ultradent). The temperature for drying also demonstrates extreme variability both in time and range, $15 \mathrm{~s}$ to $2 \mathrm{~min}$., from room temperature to over $100{ }^{\circ} \mathrm{C}$. This calls for guidelines to standardize and define the best practical approach (hair dryer, toaster oven, etc.).

One limitation of this present study was that only one CAD/CAM ceramic was tested and it was not do any aging process. Further research should be carried out to include pressable and stackable porcelain, as well as other CAD/CAM ceramics.

\section{Conclusions}

Within the limitation of this study, it was possible to conclude that etching lithium disilicate CAD/CAM ceramics, following by ultrasonic cleaning in distilled water and application of a silane, is important to enhance the adhesion resistance.

\section{Authors' contributions}

GB, AC and PM, the authors contributed with the idea, research development and writing. MG and HM, contributed with the paper review. All authors read and approved the final manuscript.

\section{Author details}

${ }^{1}$ Department of Operative Dentistry, Federal University of Alfenas (UNIFAL-MG), Alfenas, MG, Brazil. ${ }^{2}$ Department of Health 1, State University of Southwest Bahia, Itapetinga, BA, Brazil. ${ }^{3}$ Department of Restorative Dentistry, Piracicaba School of Dentistry, Campinas State University, Piracicaba, SP, Brazil. ${ }^{4}$ Department of Operative Dentistry, Federal University of Santa Catarina (UFSC), Florianópolis, SC, Brazil. ${ }^{5}$ Department of Restorative Sciences, Herman Ostrow School of Dentistry, University of Southern California, Los Angeles, CA, USA. ${ }^{6}$ St. Figueira da foz 44. Aldeia de Sagres, Lavras, MG 37200-000, Brazil.

\section{Acknowledgements}

The authors wish to express their gratitude to Ivoclar Vivadent for providing IPS e.max CAD and IPS Ceramic Etching Gel; Kerr Crop. for providing Optibond FL Adhesive and Ultradent for providing Silane. Study supported in part by CAPES Foundation 4979/11-7 (Dr. Bruzi) and CNPq 20092/2011-6 (Dr. Carvalho). The authors would like to express their gratitude to LCME-UFSC, with all the help in the SEM images.

Competing interests

The authors declare that they have no competing interests.

Availability of data and materials

Not applicable.

Consent for publication

Not applicable.

Ethics approval and consent to participate

Not applicable.

Funding

Not applicable.

\section{Publisher's Note}

Springer Nature remains neutral with regard to jurisdictional claims in published maps and institutional affiliations.

Received: 13 July 2017 Accepted: 5 October 2017

Published online: 23 October 2017

\section{References}

1. Nagai T, Kawamoto Y. Effect of hydrofluoric acid etching on bond strength of composite luting agent to lithium disilicate ceramic material. Int Chin J Dent. 2004:4:100-6.

2. Nagayassu MP, Shintome LK, Uemura ES, Araujo JEJ. Effect of surface treatment on the shear bond strength of a resin-based cement to porcelain. Braz Dent J. 2006;17:290-5.

3. Ho GW, Matinlinna JP. Evaluation of the microtensile bond strength between resin composite and hydrofluoric acid etched ceramic in different storage media. J Adhes Sci Technol. 2011:25:2671-85.

4. Roulet JF, Söderholm KJ, Longmate J. Effects of treatment and storage conditions on ceramic/composite bond strength. J Dent Res. 1995:74:381-7.

5. Jardel V, Degrange M, Picard B, Derrien G. Surface energy of etched ceramic. Int J Prosthodont. 1999;12:415-8.

6. Della Bona A, Van Noort R. Ceramic surface preparations for resin bonding. Am J Dent. 1998;11:276-80. 
7. Van Meerbeek B, Vanherle G, Lambrechts P, Braem M. Dentin- and enamel-bonding agents. Curr Opin Dent. 1992;2:117-27.

8. Pashley DH, Ciucchi B, Sano H, et al. Permeability of dentin to adhesive agents. Quintessence Int. 1993;24:618-31.

9. Van Meerbeek B, Peumans M, Gladys S, Horner JA. Three-year clinical effectiveness of four total-etch dentinal adhesive systems in cervical lesions. Quintessence Int. 1996;27:775-84.

10. Suh BI. All bond_-fourth generation dentin bonding system. J Esthet Dent. 1991;3:139-46.

11. Monticelli F, Toledano M, Osorio R, Ferrari M. Effect of temperature on the silane coupling agents when bonding core resin to quartz fiber posts. Dent Mater. 2006;22:1024-8.

12. Shen C, Oh WS, Williams JR. Effect of post-silanization drying on the bond strength of composite to ceramic. J Prosthet Dent. 2004;91:453-8.

13. Fabianelli A, Pollington S, Papacchini F, Goracci C, Cantoro A, Ferrari M, van Noort R. The effect of different surface treatments on bond strength between leucite reinforced feldspathic ceramic and composite resin. J Dent. 2010;38:39-43.

14. Filho AM, Vieira LC, Araújo E, Monteiro Júnior S. Effect of different ceramic surface treatments on resin microtensile bond strength. J Prosthodont. 2004;13:28-35.

15. Hooshmand T, van Noort R, Keshvan A. Bond durability of the resin-bonded and silane treated ceramic surface. Dent Mater. 2002;18:179-88.

16. Queiroz JR, Benetti P, Ozcan M, de Oliveira LF, Della Bona A, Takahashi FE, Bottino MA. Surface characterization of feldspathic ceramic using ATR FT-IR and ellipsometry after various silanization protocols. Dent Mater. 2012;28:18996 (Epub 2011 Oct 27).

17. Plueddemann EP. Silane coupling agent. New York: Plenum; 1991. p. 31-54.

18. Bailey LF, Bennett RJ. DICOR surface treatments for enhanced bonding. J Dent Res. 1988;67:925-31.

19. Peumans M, Van Meerbeek B, Yoshida Y, Lambrechts P, Vanherle G. Porcelain veneers bonded to tooth structure: an ultra-morphological FE-SEM examination of the adhesive interface. Dent Mater. 1999;15:105-19.

20. Phoenix RD, Shen C. Characterization of treated porcelain surfaces via dynamic contact angle analysis. Int J Prosthodont. 1995;8:187-94.

21. Magne P, Cascione D. Influence of post-etching cleaning and connecting porcelain on the microtensile bond strength of composite resin to feldspathic porcelain. J Prosthet Dent. 2006;96:354-61.

22. Belli R, Guimarães JC, Filho AM, Vieira LC. Post-etching cleaning and resin/ceramic bonding: microtensile bond strength and EDX analysis. J Adhes Dent. 2010;12:295-303.

23. Duarte S, Phark J-H, Blatz M, Sadan A. Ceramic systems: an ultrastructural study. Quintessence Dent Technol. 2009;32:42-60.

24. Pashley DH, Carvalho RM, Sano H, Nakajima M, Yoshiyama M, Shono Y, Fernandes CA, Tay F. The microtensile bond test: a review. J Adhes Dent. 1999;1:299-309.

25. Sano H, Shono T, Sonoda H, Takatsu T, Ciucchi B, Carvalho R, Pashley DH. Relationship between surface area for adhesion and tensile bond strength—evaluation of a micro-tensile bond test. Dent Mater. 1994;10:236-40.

26. Perdigão J, Gomes G, Gondo R, Fundingsland JW. In vitro bonding performance of all-in-one adhesives. Part Imicrotensile bond strengths. J Adhes Dent. 2006;8:367-73.

27. Sadek FT, Cury AH, Monticelli F, Ferrari M, Cardoso PE. The influence of the cutting speed on bond strength and integrity of microtensile specimens. Dent Mater. 2005;21:1144-9.

28. Goracci C, Sadek FT, Monticelli F, Cardoso PE, Ferrari M. Influence of substrate, shape, and thickness on microtensile specimens'structural integrity and their measured bond strengths. Dent Mater. 2004;20:643-54.

29. Ferrari M, Goracci C, Sadek F, Eduardo P, Cardoso C. Microtensile bond strength tests: scanning electron microscopy evaluation of sample integrity before testing. Eur J Oral Sci. 2002;10:385-91.

30. Ishikawa A, Shimada Y, Foxton RM, Tagami J. Micro-tensile and micro-shear bond strengths of current self-etch adhesives to enamel and dentin. Am J Dent. 2007;20:161-6.

31. Beloica M, Goracci C, Carvalho CA, Radovic I, Margvelashvili M, Vulicevic ZR, Ferrari M. Microtensile vs microshear bond strength of all-in-one adhesives to unground enamel. J Adhes Dent. 2010;12:427-33.

32. Kiyan VH, Saraceni CH, da Silveira BL, Aranha AC, Eduardo Cda P. The influence of internal surface treatments on tensile bond strength for two ceramic systems. Oper Dent. 2007;32:457-65.

33. Borges GA, Sophr AM, de Goes MF, Sobrinho LC, Chan DC. Effect of etching and airborne particle abrasion on the microstructure of different dental ceramics. J Prosthet Dent. 2003;89:479-88

34. Jones GE, Boksman L, McConnell RL. Effect of etching technique on the clinical performance of porcelain veneers. Quintessence Dent Technol. 1986;10:635-7.

35. Aida M, Hayakawa T, Mizukawa K. Adhesion of composite to porcelain with various surface conditions. J Prosthet Dent. 1995;73:464-70.

36. Luo XP, Silikas M, Wilson FHL, Watts DC. AFM and SEM study of the effects etching on IPS-Empress dental ceramic. Surf Sci. 2001:491:388-94.

37. Swift B, Walls AW, McCabe JF. Porcelain veneers: the effects of contaminants and cleansing regimens on the bond strength of porcelain to composite. Br Dent J. 1995;6:203-8.

38. Hooshmand T, van Noort R, Keshvad A. Storage effect of a pre-activated silane on the resin to ceramic bond. Dent Mater. 2004;20:635-42. 